\title{
DOES ORDINARY MORALITY IMPLY ATHEISM? A REPLY TO MAITZEN
}

\author{
ROB LOVERING
}

Santa Clara University

\begin{abstract}
Stephen Maitzen has recently argued that ordinary morality implies atheism. In the following, I argue that the soundness of Maitzen's argument depends on a principle that is implausible, what I call the Recipient's Benefit Principle: All else being equal, if an act A produces a net benefit for the individual on the receiving end of A, then one cannot have a moral obligation to prevent A. Specifically, the Recipient's Benefit Principle (RBP) must be true if premise (2) of Maitzen's argument is to be true. But, RBP is likely false, as it generates counterintuitive implications as well as conflicts with another principle both plausible and seemingly adopted by most of us, what I call the Preventing Immorality Principle: All else being equal, if an act $\mathrm{A}$ is seriously immoral, then one has a moral obligation to prevent $\mathrm{A}$.
\end{abstract}

\section{INTRODUCTION}

Stephen Maitzen has recently argued that ordinary morality implies atheism. ${ }^{1}$ His argument turns on an alleged inconsistent triad: (1) the belief that God exists, (2) the belief that theodical individualism is true, and (3) the belief that ordinary morality is true. By "God," he means the god of classical theism. By "theodical individualism" (TI), he is referring to the view that, necessarily, God permits undeserved, involuntary human suffering only if such suffering ultimately produces a net benefit for the sufferer. And by "ordinary morality," well, it isn't altogether clear what he is referring to ("I won't define 'ordinary morality'," Maitzen writes, believing that there is no sharp definition of $\mathrm{it}^{2}$ ), but he writes of an obligation that he believes belongs to it uncontroversially, namely, the obligation to prevent easily preventable horrific suffering by an innocent sufferer.

\footnotetext{
${ }^{1}$ Stephen Maitzen, “Ordinary Morality Implies Atheism," European Journal for Philosophy of Religion 2 (2009): 107-126.

${ }^{2}$ Maitzen, 108.
} 
Maitzen presents his argument in his aptly titled "Ordinary Morality Implies Atheism." The argument is as follows:

1) If God exists and TI is true, then, necessarily, all undeserved, involuntary human suffering ultimately produces a net benefit for the sufferer.

2) If, necessarily, all undeserved, involuntary human suffering ultimately produces a net benefit for the sufferer, then (a) we never have a moral obligation to prevent undeserved, involuntary human suffering or (b) our moral obligation to prevent undeserved, involuntary human suffering derives entirely from God's commands.

3) We sometimes have a moral obligation to prevent undeserved, involuntary human suffering, an obligation that does not derive from God's commands.

4) So: It isn't the case that, necessarily, all undeserved, involuntary human suffering ultimately produces a net benefit for the sufferer. [From (2), (3)]

5) So: God does not exist or TI is false. [From (1), (4)]

6) If not even God may treat human beings merely as means, then TI is true.

7) Not even God may treat human beings merely as a means.

8) So: TI is true. [From (6), (7)]

9) So: God does not exist. [From (5), (8) $]^{3}$

In the following, I argue that the soundness of Maitzen's argument depends on a principle that is implausible. I call the principle in question the "Recipient's Benefit Principle" or "RBP." It is as follows:

Recipient's Benefit Principle: All else being equal, if an act A produces a net benefit for the individual on the receiving end of $\mathrm{A}$, then one cannot have a moral obligation to prevent $\mathrm{A}$.

Specifically, RBP must be true if premise (2) is to be true. ${ }^{4}$ But, RBP is likely false, as it generates counterintuitive implications as well as conflicts

${ }^{3}$ Maitzen, $111 \mathrm{ff}$.

${ }^{4}$ In another critique of Maitzen's argument, Jerome Gellman challenges premise (2) as well. But the natures of our respective challenges and, in turn, critiques have virtually nothing in common. Accordingly, Maitzen's reply to Gellman has virtually nothing to do with my critique. See Jerome Gellman, “On God, Suffering, and Theodical Individualism," European Journal for Philosophy of Religion 1 (2010): 187-191; Stephen Maitzen, “On Gellman's Attempted Rescue,” European Journal for Philosophy of Religion 1 (2010): 193-198. 
with another principle both plausible and seemingly adopted by most of us, one I refer to as the "Preventing Immorality Principle," or "PIP":

Preventing Immorality Principle: All else being equal, if an act A is seriously immoral, then one has a moral obligation to prevent A.

Before moving on, it should be emphasized that throughout the following, unless otherwise noted, statements such as "Jones has a moral obligation to prevent David's immolation" and "We ought to prevent the seriously immoral acts of others" are to be understood as all-else-being-equal claims. Such statements arise often, and one would misunderstand the following critique if one were to construe claims as all-things-considered claims when they're not.

\section{MAITZEN ON (2) AND ITS IMPLICATIONS}

Again, premise (2) is as follows: If, necessarily, all undeserved, involuntary human suffering ultimately produces a net benefit for the sufferer, then (a) we never have a moral obligation to prevent undeserved, involuntary human suffering or (b) our moral obligation to prevent undeserved, involuntary human suffering derives entirely from God's commands. Maitzen's defense of premise (2) consists almost entirely of a thought experiment involving vaccination. "We know," Maitzen writes,

that some vaccines can cause serious side-effects, but suppose that an abundantly available vaccine were, despite the painfulness of receiving it, known to produce a net benefit (the painfulness included) for everyone who receives it. Suppose, further, that no less painful a procedure produces the same benefit. Under those circumstances, how could we ever have a moral obligation to prevent vaccination? I can't see how we could. ${ }^{5}$

If this is correct, Maitzen reasons, then, given God's existence and TI, either we have no obligation to prevent undeserved, involuntary human suffering or, if we do, then the obligation must derive entirely from God's commands. For, together, God's existence and TI guarantee that any case involving undeserved, involuntary human suffering produces a net benefit for the victim. And, to use Maitzen's language, under those circumstances, how could we ever have a moral obligation to prevent undeserved, involuntary human suffering? Maitzen, for one, can't see how we could unless the moral obligation is derived entirely from God's commands.

\footnotetext{
${ }^{5}$ Maitzen, 111.
} 
With this in mind, consider another thought experiment employed by Maitzen, this time involving a small boy who is about to be set on fire by his father (based on an actual case involving a six-year-old boy named "David" and David's father, "Charles"). Given ordinary immorality, Maitzen contends, "if you can easily and at no risk to yourself prevent the total immolation of a small boy who is about to be set on fire by his abusive father, you ought to prevent it." ${ }^{6}$ Yet, if God exists and TI is true, Maitzen argues, then it's not the case that you ought to prevent the boy's immolation-i.e., you have no obligation to do so - since the immolation produces a net benefit for the boy.

Something, then, has to give, Maitzen reasons - one cannot consistently believe that God exists, that TI is true, and that ordinary morality is true (specifically, that we have an obligation to prevent easily preventable horrific suffering by an innocent sufferer). Of the three, of course, Maitzen argues that one should retain belief in TI and ordinary morality and jettison belief in God's existence.

\section{AN ANTICIPATED OBJECTION}

Before moving on to my own objections, I'd like to draw the reader's attention to one of the many objections Maitzen anticipates and responds to. It is as follows: Respect for the autonomy of persons sometimes gives us a moral obligation to prevent undeserved, involuntary human suffering; accordingly, respect for autonomy gives us a moral obligation to prevent David's immolation.

Maitzen rejects this respect-for-autonomy based objection, arguing as follows:

For suppose that David were unwilling to receive a vaccination of the kind I described above: abundantly available and known to produce a net benefit (painfulness included) for everyone who receives it. It is by no means clear that anyone has an ordinary moral obligation to prevent the vaccination, despite six-year-old David's unwillingness to receive it. Since we have an ordinary moral obligation to prevent David's immolation but no such obligation to prevent his vaccination, autonomy does not work here, for it's equally present (or absent) in both cases. ${ }^{?}$

\footnotetext{
${ }^{6}$ Maitzen, 108.

${ }^{7}$ Maitzen, 112.
} 
The reason for my calling attention to this particular objection-as well as to Maitzen's reply to it - will be made evident shortly.

\section{ON THE RECIPIENT’S BENEFIT PRINCIPLE}

The reasoning behind Maitzen's judgments in the vaccine and immolation cases requires that RBP be true: that, if an act A produces a net benefit for the individual on the receiving end of $A$, then one cannot have a moral obligation to prevent A, all else being equal. For, essentially, Maitzen reasons in the following way:

(i) The vaccine (or, immolation) produces a net benefit for David.

(ii) Therefore, one cannot have a moral obligation to prevent the vaccine (or, immolation).

The preceding argument is, of course, enthymematic, the suppressed premise being: If the vaccine (or, immolation) produces a net benefit for David, then one cannot have a moral obligation to prevent it. The reasoning behind Maitzen's judgments in the vaccine and immolation cases, then, involves a premise which is a token of RBP. So, if RBP - let alone any token of it-is not true, then Maitzen's judgments in these cases is not derivable from the premises.

The question, then, is: Is RBP true? There is reason to think it is not. The case I will present against RBP is twofold. First, I shall argue that RBP generates counterintuitive implications. Second, I shall argue that RBP conflicts with a principle both plausible and seemingly embraced by most of us, namely, the Preventing Immorality Principle (PIP). Each objection will be examined in turn.

\section{RBP's Counterintuitive Implications}

The objection pertaining to RBP's counterintuitive implications is rather straightforward and may be stated succinctly. Suppose that undergoing an invasive surgery will produce a net benefit for Smith. Suppose, further, that Smith - a standard adult human being — has rational grounds for not wanting to undergo the invasive surgery. Suppose, finally, that Smith's physician is about to force Smith to undergo the invasive surgery against his will. Given RBP, one cannot have a moral obligation to prevent the physi- 
cian's forced invasive surgery of Smith, all else being equal. But this is strongly counterintuitive. (Cases like this, of course, could be generated ad nauseum, but one will suffice for present purposes.) RBP, then, generates counterintuitive implications and, thus, is likely false.

\section{RBP and the Preventing Immorality Principle}

But the case against RBP need not rest on intuition alone. Consider that, despite the fact that the invasive surgery will produce a net benefit for Smith, most people would likely agree that the physician's forcing Smith to undergo the surgery against his will is seriously immoral. Moreover, most people would likely agree (or so shall I argue below) that, given the serious immorality of the act, one has a moral obligation to prevent it. More generally, most people would likely agree that, if an act A produces a net benefit for the individual on the receiving end of A but is nevertheless seriously immoral, then one has a moral obligation to prevent A. In other words, most people likely accept PIP: All else being equal, if an act A is seriously immoral, then one has a moral obligation to prevent $\mathrm{A}$.

With PIP in mind, let us consider again Maitzen's two thought experiments, beginning with the one involving vaccination. Maitzen states that he cannot see how we could ever have a moral obligation to prevent a vaccination that is known to produce a net benefit for everyone who receives it. Well, if PIP is true, then we could have a moral obligation to prevent such a vaccination. After all, that administering such a vaccination would produce a net benefit for those to whom it is administered does not, by itself, entail that administering such a vaccination is morally permissible. And, if administering such a vaccination is seriously immoral and PIP is true, then we not only could but do have a moral obligation to prevent such a vaccination.

Similarly, if PIP is true, then we could have a moral obligation to prevent the immolation. After all, that the immolation would produce a net benefit for the boy does not, by itself, entail that setting the boy on fire is morally permissible. And, if setting the boy on fire is seriously immoral and PIP is true, then we not only could but do have a moral obligation to prevent the immolation of the boy.

All this to say, given RBP, one cannot have an obligation to prevent the vaccine or immolation, all else being equal; while, given PIP, one can have an obligation to prevent them, all else being equal. RBP and PIP, then, conflict and cannot both be true.

What's more - and more to the point-if PIP is true and is so independent of God's commands, then premise (2)'s consequent is a false dichoto- 
my. For, if PIP is true, then one can have a moral obligation to prevent undeserved, involuntary suffering even if the suffering produces a net benefit for the sufferer, namely, when the inflicting of such suffering is seriously immoral. And if PIP is true independent of God's commands, then it is an obligation one can have independent of God's commands. That PIP is true and is so independent of God's commands will be defended hereafter.

\section{DEFENDING PIP}

Though there may be numerous arguments for PIP, two will suffice for present purposes. The first I will refer to as the "Conceptual Argument" as it appeals to the concept of an immoral act. The second I will refer to as the "Argument from Explanatory Power" as it appeals to PIP's power to explain the moral judgments we have in a wide variety of cases. I will consider each argument in turn.

\section{The Conceptual Argument}

As for the Conceptual Argument, on virtually any account of the nature of morality, an immoral act is an act that one ought not perform (nonprudentially speaking, typically), an act that one has a moral obligation to refrain from performing. What this means for any one of us is that, when one is tempted to engage in an immoral act, one ought to prevent oneself from engaging in it.

But what if one refuses to prevent oneself from engaging in the immoral act? That is, what if one refuses to prevent oneself from doing that which ought not be done? Does it follow that one no longer has an obligation to refrain from performing the immoral act? Of course not- one still has a moral obligation to refrain from performing the immoral act despite one's refusal to prevent oneself from doing that which one ought not do. The question, then, is whether someone else has-better, perhaps, whether someone else acquires - a moral obligation to prevent the immoral act one refuses to prevent oneself from doing.

Now, answering this question thoroughly would take us too far afield of the present topic as it would require me to lay out and defend a theory of the nature of morality and, in particular, moral obligations. It will have to suffice, then, simply to note that most of us seem to believe that people have a moral obligation to prevent the immoral acts of others, at least those acts that are seriously immoral. For example, if, unbeknownst to oneself 
but in full awareness of others, someone were about to, say, kidnap one's child, one would expect others to prevent the individual from doing so, particularly when they can do so easily and at little cost to themselves. This expectation is evidenced by (among other things) our reactions to those who fail to prevent the seriously immoral acts of others - we tend to be extremely disappointed if not outraged. But, disappointment and outrage are appropriate reactions to another's failure to do something only when there is an expectation that the other do what she (subsequently) failed to do. Accordingly, our disappointment and outrage are appropriate reactions to someone's failure to prevent another's seriously immoral act only when there is an expectation that she do so.

Of course, even if this is correct, it's an open question as to why we have this expectation. And, from the fact that we do have this expectation, it does not immediately follow that we do because we believe that others have a moral obligation to prevent someone else's seriously immoral act. That said, the latter strikes me as the best explanation as to why we expect this, at least, relative to many reasonable alternative explanations.

Consider, for example, the following possible explanation for why we expect others to prevent someone else's seriously immoral act: we expect this of others because we believe that we (those of us who expect this) stand to benefit from others preventing someone else's doing so. But this explanation is inadequate since we don't always benefit from others preventing serious immorality - particularly when the seriously immoral act they are preventing is one's own! Consider, also, the explanation that we expect this of others because we believe that they (those doing the preventing) stand to benefit from their preventing someone else's doing so. But, similarly, this explanation is inadequate since they don't always benefit from preventing someone else's seriously immoral act. Finally, consider the explanation that we expect this of others because we believe that society (i.e., all of us - both "we" and "they") stands to benefit from their preventing someone else's doing so. But, once again, this explanation is inadequate since society doesn't always benefit from others preventing someone else's seriously immoral act. There may be other explanations for why we expect others to prevent someone else's seriously immoral act, of course, but for present purposes I'll stop here and simply submit that, relative to these explanations, the explanation that we do because we believe they have a moral obligation to do so is most plausible.

Moreover, this explanation fits well with real cases, such as the murders of Kitty Genovese and Sherrice Iverson. Regarding the latter, consider most people's reaction to David Cash's failure (to attempt) to prevent his friend 
from raping and killing Sherrice Iverson in 1997. Explaining himself to the Los Angeles Times, Cash said, "I'm not going to get upset over somebody else's life. I just worry about myself first." ${ }^{\prime \prime}$ The reaction to Cash's failure to prevent his friend from raping and killing the girl — to say nothing of his explanation for his behavior - was nothing short of outrage. And, the outrage was clearly a function of the expectation that he not only prevent his friend's seriously immoral acts but do so because his friend's acts were seriously immoral. ${ }^{9}$ Most people reacted similarly to the thirty-eight individuals' failure (to attempt) to prevent Kitty Genovese's murder. ${ }^{10}$

All this to say, our expectations of - evidenced by our reactions toother people's failure to prevent seriously immoral acts indicate that most of us think that people have a moral obligation to prevent the seriously immoral acts of others, particularly when they can do so easily and at little cost to themselves. In other words, most of us seem to embrace PIP.

\section{The Argument from Explanatory Power}

As for the Argument from Explanatory Power, PIP can explain judgments we have in a wide variety of cases. PIP can explain our judgment in the Smith case, for example - one can have a moral obligation to prevent the physician's forced invasive surgery of Smith because it is seriously immoral. It can also explain our judgments in the immolation and vaccination cases. Specifically, PIP can explain the judgment that we have a moral obligation to prevent six-year-old David's immolation but not his vaccination, as the immolation is seriously immoral while the vaccination is not. PIP can even explain the judgment that we would be obligated to prevent someone's vaccination under certain conditions. Consider, again, Maitzen's reply to the respect-for-autonomy based objection to his argument:

For suppose that David were unwilling to receive a vaccination of the kind I described above: abundantly available and known to produce a net benefit (painfulness included) for everyone who receives it. It is by no means clear that anyone has an ordinary moral obligation to prevent the vaccination, despite

\footnotetext{
${ }^{8} \mathrm{http} / /$ articles.latimes.com/1998/jul/19/news/mn-5552/16

${ }^{9}$ The reaction of the District Attorney who worked the case, Stewart Bell, is notable in this regard. Bell referred to Cash's failure to prevent his friend from raping and killing the girl as a "moral transgression." But it's hard to see how Bell could consider Cash's failure to prevent his friend's actions to be a moral transgression if he did not believe that Cash had a moral obligation to prevent such acts and had it because (at least in part) the acts were seriously immoral. See, http://articles.latimes.com/1998/sep/16/news/mn-23165.

${ }^{10} \mathrm{http}: / /$ en.wikipedia.org/wiki/Kitty_Genovese\#Public_Reaction
} 
six-year-old David's unwillingness to receive it.

So far, so good. But consider another vaccination case which is identical in every respect to the vaccination case involving David save for one: rather than involving six-year-old David, it involves a thirty-six-year-old standard adult man named "John." Unlike in the vaccination case involving David, it seems rather clear that one can have an obligation to prevent John's vaccination given his unwillingness to receive it. For forcing John to receive a benefit against his will violates his bodily autonomy and is thereby seriously immoral. Indeed, the case of John is relevantly analogous to the case of the physician's forcing Smith to undergo invasive surgery against his will. And, once again, PIP can explain this judgment.

And though some might think that the preceding is inconsistent with the judgment that we have no obligation to prevent six-year-old David's vaccination, such is not the case. There is, after all, a significant disanalogy between David, on the one hand, and John, on the other. Autonomy, it is commonly (and plausibly) believed, is a degreed property. And, John, qua thirty-six-year-old standard adult man, is clearly autonomous to the degree such that violations of his autonomy are rightly considered to be seriously immoral. David, on the other hand, qua six-year-old child, is not clearly autonomous to the degree such that violations of his autonomy are rightly considered to be seriously immoral. ${ }^{11}$ Accordingly, though violating John's autonomy by forcing him to receive a benefit against his will is (or, at least, can be) seriously immoral, violating David's autonomy forcing him to receive a benefit against his will is not.

The Conceptual Argument and the Argument from Explanatory Power give us good reason to think PIP is true. But, before moving on, I would like to note that, beyond these arguments, there may be yet another reason to embrace PIP, one particularly pertinent to Maitzen's argument: PIP may be a constitutive principle of ordinary morality itself. As Maitzen correctly notes in his article, there is no sharp definition of ordinary morality, so fixing which principles are and which principles are not constitutive of ordinary morality (if any) can be difficult, perhaps prohibitively so. That said, upon first and even subsequent glances, PIP strikes me as a plausible candidate for being constitutive of ordinary morality; indeed, much more plausible a candidate than RBP, and (as nearly) as plausible a candidate as the moral obligation to prevent easily preventable, horrific suffering by an innocent person.

${ }^{11}$ At what point someone crosses the threshold from being insufficiently autonomous to being sufficiently autonomous is, for present purposes, inconsequential. 


\section{IS PIP TRUE INDEPENDENT OF GOD’S COMMANDS?}

Assuming PIP is true and we have a moral obligation to prevent serious immorality, must PIP be derived from God's commands, given (2)'s antecedent - that, necessarily, all undeserved, involuntary human suffering ultimately produces a net benefit for the sufferer? I see no reason why this must be the case unless all moral obligations must be derived from God's commands. But that all moral obligations must be derived from God's commands is implausible for various reasons, the primary of which is that all moral obligations simply can't be derived from God's commands.

To see this, let us assume that we have a moral obligation to assist others who are in need. If all moral obligations must be derived from God's commands, then what makes this true is that God has commanded us to assist others who are in need. But, if all moral obligations must be derived from God's commands, then it is true that we have this specific moral obligation only if it is also true that we have a moral obligation to obey God's commands in general. But therein lies the rub, since, given this, there must be at least one moral obligation that does not derive from God's commands. As Stephen Darwall writes,

Unless it is true that we ought to do what God commands in general, quite independent of whether He commands us to do what He commands, God's specific commands cannot generate specific duties. So, according to this rationale for following God's commands, there must be at least one moral fact [or, for our purposes, moral obligation] that God does not create by commandnamely, that we ought to obey His commands. ${ }^{12}$

If this is correct, then it is false that all moral obligations can belet alone must be - derived from God's commands, even given (2)'s antecedent.

\section{SUMMARY}

To sum up, I have argued thus far that:

(a) the reasoning behind Maitzen's judgments in the vaccine and immolation cases and, in turn, premise (2) requires that RBP be true;

(b) RBP is likely false, as it generates counterintuitive implications as

\footnotetext{
${ }^{12}$ Stephen Darwall, Philosophical Ethics (Boulder, CO: Westview Press, 1998), 45.
} 
well as conflicts with PIP;

(c) the truth of PIP need not be derived from God's commands;

(d) given PIP being true independent of God's commands, premise (2)'s consequent is a false dichotomy.

Given all of this-specifically, given premise (2)'s consequent being a false dichotomy - it follows that:

(e) if premise (2)'s antecedent is true, then premise (2) is false; while, if premise (2)'s antecedent is false, then premise (1)'s consequent is false. ${ }^{13}$

And, if premise (1)'s consequent is false, it follows that:

(f) if premise (1)'s antecedent is true, then premise (1) is false; while, if premise (1)'s antecedent is false, then a solution arises to the inconsistent triad at the heart of Maitzen's argument: it is false both that God exists and that TI is true.

In any case, Maitzen's argument from ordinary morality to atheism is undermined.

\section{An Initial Reply \\ (Or, On the Relation Between Ordinary Morality and RBP)}

Maitzen has correctly pointed out to me that, "In order for PIP to apply to Charles's burning of David, Charles's action must be immoral." 14 So, is Charles's burning of David immoral? Well, if ordinary morality has anything to say about this, it most certainly is, or so I shall argue. You see, if ordinary morality tells us anything, it is that Charles's burning of David is seriously immoral, even if it will produce a net benefit for David - just as, I submit, it tells us that the physician's forcing Smith to undergo an invasive surgery against his will is immoral, even if it will produce a net benefit for him. For, ordinary morality is, in certain respects, deontological in nature. As Shelly Kagan - a foremost critic of ordinary morality—writes: "[A] feature of ordinary morality is that it lays down certain strict limits on our actions - forbidding various types of acts even if the best consequences

\footnotetext{
${ }^{13}$ According to classical logic, when a conditional statement's antecedent is true but its consequent is false, the truth value of the statement is false.

${ }^{14}$ Maitzen, e-mail correspondence.
} 
overall could be achieved only by performing such an act." ${ }^{15}$ And if ordinary morality forbids various types of acts even if the best consequences overall could be achieved only by performing such an act, then surely it also forbids various types of acts even if the best consequences solely for the individual on the receiving end of such acts could be achieved only by performing such an act. And, if any act is an instantiation of a type of act forbidden by ordinary morality, it's the immolation of David.

Of course, Maitzen may not agree with my claim that, according to ordinary morality, David's immolation is seriously immoral even if it will produce a net benefit for him. Indeed, Maitzen's understanding of ordinary morality may include a principle very similar to but distinct from RBP (the difference having to do with what's stated in the consequent), what I'll refer to as the "Recipient's Benefit Principle*", or "RBP*":

Recipient's Benefit Principle*: All else being equal, if an act A produces a net benefit for the individual on the receiving end of $\mathrm{A}$, then $\mathrm{A}$ cannot be immoral.

Now, if Maitzen's understanding of ordinary morality does indeed include RBP*, then my reply is: so much the worse for Maitzen's understanding of ordinary morality and, with it, his argument from ordinary morality to atheism. As moral principles go, RBP* is implausible. It is overly narrow and unusually consequentialist as it renders the moral permissibility of an act a function of merely the goodness of the consequence for a single individual, namely, the individual on the receiving end of the act. And, that the moral permissibility of an act is a function of merely the goodness of the consequence for a single individual is simply implausible. Ironically, there's no better demonstration of this then Maitzen's own immolation case! All this to say, if Maitzen's understanding of ordinary morality includes $\mathrm{RBP}^{*}$, then his argument from ordinary morality to atheism relies upon an implausible principle (RBP*), one which, to my knowledge, no philosopher has ever accepted, consequentialists notwithstanding.

To motivate further the preceding point, consider the following analogy. Suppose someone presented an argument for atheism that relied upon ethical egoism, the theory that an act A is morally right if it produces the best overall consequences for the actor himself or herself. Suppose also that the argument was valid - that ethical egoism did indeed entail atheism. What then? Would we thereby have good reason to embrace atheism? We would only if ethical egoism itself were a plausible moral theory. But

${ }^{15}$ Shelly Kagan, The Limits of Morality (New York, NY: Oxford University Press, 1989), 4. 
ethical egoism isn't a plausible moral theory, or so many of us believe. Accordingly, such an argument would not give (many of) us a good reason to embrace atheism. Similarly, if Maitzen's understanding of ordinary morality includes RBP*, then his argument from ordinary morality to atheism does not give (many of) us a good reason to embrace atheism.

If, on the other hand, Maitzen's understanding of ordinary morality does not include RBP*_-more specifically, if Maitzen rejects RBP*_then premise (2)'s consequent is a false dichotomy, given PIP being true independent of God's commands. For, rejecting RBP* amounts to accepting that an act A can be (if not, at times, is) seriously immoral even if it produces a net benefit for the individual on the receiving end of A. This, combined with PIP being true independent of God's commands, renders premise (2)'s consequent a false dichotomy. And, as stated above (see (e) and (f) above), if premise (2)'s consequent is a false dichotomy, then Maitzen's argument from ordinary morality to atheism is undermined.

\section{A Final Reply: Implications of PIP}

Given what I have argued thus far, one might reasonably wonder: If PIP is true and is so independent of God's commands, then doesn't this entail that, like us, God himself (if he exists) has a moral obligation to prevent seriously immoral acts? For example, in the immolation case, doesn't Godlike us - have an all-else-being-equal obligation to prevent the boy's immolation, given PIP? It seems he does.

However, it does not follow from this that both we and God have an allthings-considered obligation to prevent the boy's immolation. Specifically, it may be that we have an all-things-considered obligation to prevent the boy's immolation but that God doesn't. You see, God may have sufficient reasons for allowing the boy's immolation - reasons that include but nevertheless go beyond the net benefit produced for the boy-while we may not. (What those reasons may be is, for present purposes, irrelevant, since all I am trying to establish at the moment is the logical possibility that we can have an all-things-considered obligation to prevent the boy's immolation even when God doesn't.)

Now, suppose that God does indeed have sufficient reasons for allowing the boy's immolation but Jones does not. To be sure, Jones may be aware of the fact that, if God has sufficient reasons to allow the immolation, then God may indeed allow the immolation, while, if God does not have sufficient reasons to allow the immolation, then God will not allow the immolation. What Jones is not aware of is whether God does indeed 
have such reasons. The question, then, is whether God's having sufficient reasons for allowing the boy's immolation releases Jones of an all-thingsconsidered obligation to prevent the seriously immoral act of immolation, despite Jones not knowing whether God does indeed have sufficient reasons for allowing the immolation. It seems not. To see this, consider the following analogy.

Suppose both Miller and Lewis have the opportunity to prevent the boy's immolation. Suppose also that Miller possesses sufficient reasons for allowing the boy's immolation but Lewis does not. Specifically, Miller knows that, if anyone prevents David's immolation, David's uncle and his cohorts will subsequently snatch David from the one who prevented the immolation, torture David as well as David's siblings for weeks on end, and then light them all on fire. Lewis, on the other hand, does not know about the uncle and his conditional plans. All Lewis knows is that the boy's immolation would be seriously immoral, even if the immolation were to produce a net benefit for the boy (given, at any rate, my understanding of ordinary morality, as stated above). Does Miller's knowledge of the uncle's conditional plans release Lewis of his moral obligation to prevent the immolation, given the serious immorality of the immolation and PIP? It seems not.

If the preceding is correct, then the fact that God has a reason for allowing the boy's immolation and, thus, does not have an all-things-considered obligation to prevent it does not entail that Jones - or anyone else, for that matter-does not have an all-things-considered obligation to prevent it. Moreover, if Jones does not have God's reason for allowing the boy's immolation and everything else is equal, then, given PIP, Jones has an allthings-considered obligation to prevent the boy's immolation due to its immorality.

\section{Conclusion}

I have argued here that the soundness of Maitzen's argument depends on a principle, RBP, that is implausible, as it generates counterintuitive implications as well as conflicts with a principle both plausible and seemingly adopted by most of us, PIP. I have also considered the possibility that Maitzen embraces RBP* - that, all else being equal, if an act A produces a net benefit for the individual on the receiving end of $A$, then A cannot be immoral - and, thus, that PIP does not apply to the immolation case. In reply, I have argued that, like RBP, RBP* is implausible. Finally, I have argued that, though PIP applies to God (if God exists), it does not follow 
from this that, in cases where God does not have an all-things-considered obligation to prevent serious immorality, we, too, do not have an all-thingsconsidered obligation to prevent serious immorality. 
Copyright of Forum Philosophicum: International Journal for Philosophy is the property of Forum Philosophicum and its content may not be copied or emailed to multiple sites or posted to a listserv without the copyright holder's express written permission. However, users may print, download, or email articles for individual use. 